\title{
Causes of death in children with insulin dependent diabetes 1990-96
}

\author{
Julie A Edge, Martha E Ford-Adams, David B Dunger
}

\begin{abstract}
Background-Mortality rates in children with insulin dependent diabetes (IDDM) in the UK are unknown and the causes of death not well documented.

Aim-To determine the mortality rate and causes of death in children with IDDM. Methods-The Office of National Statistics (England and Wales) and the General Register Office (Scotland) notified all deaths under 20 years of age from 1990 to 1996 with diabetes on the certificate. Further details were provided by coroners, pathologists, and clinicians.

Results-116 deaths were notified and 83 were caused by diabetes. The standardised mortality ratio was 2.3 (95\% confidence interval (CI), 1.9 to 2.9 ), being highest in the age group 1-4 years, at 9.2 ( $95 \% \mathrm{CI}, 5.4$ to 14.7$)$. Of the 83 diabetic deaths, hyperglycaemia/diabetic ketoacidosis (DKA) was implicated in 69 and hypoglycaemia in 7. Cerebral oedema was the most common cause of death in young children ( 25 of 36 diabetes related deaths in children under 12 years of age). 34 young people (10-19 years; 24 male) were either found dead at home $(n=26)$ or moribund on arrival at hospital $(n=8)$. In 24 of these, it appeared that DKA was the cause of death, in four hypoglycaemia was likely. Nine of these were found "dead in bed".

Conclusions-Children with IDDM have a higher mortality than the general population. Cerebral oedema accounts for most hospital deaths in young children. There are a large number of young men dying at home from neglected IDDM. Early diagnosis of IDDM in children and closer supervision of young people might prevent some of these deaths.

(Arch Dis Child 1999;81:318-323)
\end{abstract}

Keywords: mortality; cerebral oedema; diabetic ketoacidosis; hypoglycaemia

Department of Paediatrics, John Radcliffe Hospital, Headington, Oxford OX3 9DU, UK

$\mathrm{J}$ A Edge

M E Ford-Adams

D B Dunger

Correspondence to: Dr Edge.

email: julie.edge@ paediatrics.ox.ac.uk

Accepted 25 June 1999 oedema in the UK is unknown. In the U $50 \%$ of DKA related deaths between 1950 and 1985 were caused by cerebral oedema, ${ }^{1}$ and cerebral oedema is now the most common cause of death at the onset of IDDM in Sweden. ${ }^{7}$ However, in a recent register based study of diabetes mortality in Yorkshire, UK, of 15 deaths caused by diabetes, eight were the result of DKA, but only two of these were thought to have had cerebral oedema. ${ }^{4}$ Moreover, in a previous study of deaths in people with IDDM under the age of 50 in the UK, DKA accounted for 16 of the 23 deaths in patients under 20 years of age, but cerebral oedema was not mentioned. ${ }^{5}$ Therefore, it is not clear whether cerebral oedema is an important problem in the UK.

Sudden unexpected death in bed has recently been reported to be an increasingly common cause of death in young adults with IDDM in Sweden. ${ }^{7}$ There have also been reports from the UK of young people who have died in their sleep, ${ }^{38}$ but the most recent study did not specify whether patients were found dead at home. ${ }^{4}$ It has been suggested that hypoglycaemia might be responsible for some of these unexpected deaths in adults. ${ }^{8}$ Given the increased likelihood of hypoglycaemia in children treated with intensive insulin regimens, it is essential to know whether hypoglycaemia might be contributing to any sudden and unexpected deaths in children.

We undertook our study to resolve the uncertainties over the causes of death in young people under the age of 20 years in the UK. The aims of our study were to determine how many deaths in children and young people with IDDM are a result of DKA and how many of these are caused by cerebral oedema. In addition, if children are dying suddenly and unexpectedly at home, how many of these deaths are attributable to hypoglycaemia? The final aim was to determine the mortality rate in children and young people with IDDM compared with the general population.

\section{Methods}

The Office of National Statistics (ONS, formerly the Office of Population Censuses and Surveys) in England and Wales, and the General Register Office for Scotland were asked to provide details of all young people under the age of 20 years where diabetes mellitus appeared on the death certificate during the period 1990-96. Information reported included the name, date of birth, date and place of death, and the causes of death as they appear on the death certificate.

In cases where diabetes might have contributed to death, a questionnaire was sent to either the senior hospital clinician involved in the patient's terminal illness, or the coroner (in 


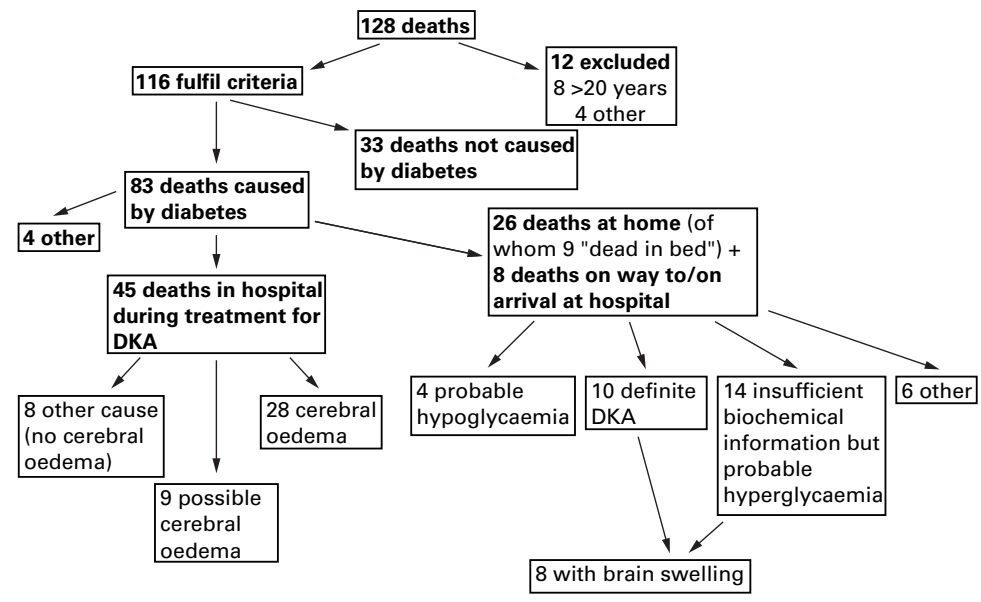

Figure 1 Flow diagram showing breakdown of causes of death.

England and Wales) or procurator fiscal (in Scotland) who investigated the death, or both. They were asked for details of the cause of death and whether there was any evidence of cerebral oedema, either clinically, radiologically, or at necropsy. Copies of reports and submissions to coroners were requested, including the necropsy report and biochemistry and toxicology results. The medical records of these patients have not been examined.

DEFINITION OF TERMS

When the death certificate contained the phrases "diabetic ketoacidosis", "hyperglycaemic coma", or "diabetic coma", this was only assumed to be DKA if confirmed by the clinician, or where high glucose and ketone concentrations (either blood glucose $>30 \mathrm{mmol} / 1$ with ketones or a blood glucose $>50 \mathrm{mmol} / 1$ alone) were found at necropsy. If hypoglycaemia was mentioned on the death certificate, the evidence either from clinicians or at necropsy was scrutinised to determine the presence of any objective evidence. The presence of cerebral oedema was confirmed either radiologically or at necropsy (or both) in most of the cases $(n=24)$, but by a classic history alone in four cases.

\section{STATISTICAL ANALYSIS}

In the absence of accurate national statistics, the population of young people with IDDM in the UK was calculated from three sources, namely: (1) the incidence of IDDM in the Oxford region in $1985-86,{ }^{9}$ (2) incidence figures updated to $1995,{ }^{10}$ and (3) the Yorkshire register based survey. ${ }^{4}$ The death rates

Table 1 Breakdown of the 83 diabetes related deaths (by year of death)

\begin{tabular}{lllll}
\hline \multicolumn{5}{c}{ Number of deaths from diabetes } \\
\cline { 2 - 4 } Year of death & $\begin{array}{l}\text { England and } \\
\text { Wales }\end{array}$ & Scotland & Total & $\begin{array}{l}\text { Deaths caused by DKA with } \\
\text { cerebral oedema }\end{array}$ \\
\hline 1990 & 12 & 2 & 14 & 3 \\
1991 & 11 & 4 & 15 & 7 \\
1992 & 10 & 1 & 11 & 3 \\
1993 & 13 & 2 & 15 & 6 \\
1994 & 10 & 0 & 10 & 5 \\
1995 & 13 & 2 & 15 & 3 \\
1996 & 3 & 0 & 3 & 1 \\
Totals & 72 & 11 & 83 & 28 \\
\hline
\end{tabular}

DKA, diabetic ketoacidosis.

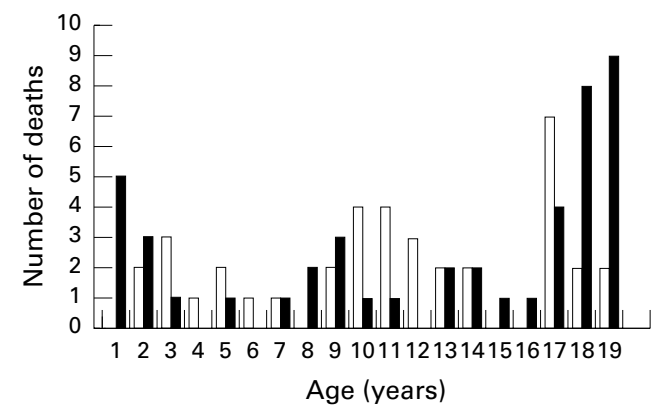

Figure 2 Number of deaths by age in male (closed bars) and female (open bars) patients with insulin dependent diabetes mellitus.

and childhood population in England and Wales for age bands between 1 and 19 years were taken from data obtained from the Office of National Statistics, 1990-96. Standardised mortality ratios (SMRs) were calculated and 95\% confidence intervals (CI) determined using limit factors for a Poisson distributed variable. $^{11}$

Our study was approved by the central Oxford research ethics committee, and patient confidentiality was maintained by coding. The families of the deceased were not approached.

\section{Results}

The total number of deaths notified was 128 . Twelve reports were excluded because they did not fulfill the requested criteria; eight were over the age of 20 years, two died from diabetes insipidus, one from asthma, and one from hyperosmolar coma after investigation of growth hormone deficiency. Thus, for the seven year period (1990-96) there were 116 deaths fulfilling the criteria requested. Figure 1 is a flow diagram showing the number of deaths from each cause.

In 33 patients diabetes did not contribute to the death. In 25 of these patients, death was the result of a severe underlying disease (such as cystic fibrosis), and the child either had secondary or incidental diabetes, which was well controlled. These were not included in the analysis of mortality rate for diabetes because they were not considered to have primary diabetes. In the other eight patients, the child had well controlled IDDM but died from another incidental cause (for example malignancies); these deaths were included in mortality rate analysis.

There were therefore 83 deaths as a direct result of diabetes (table 1). Figure 2 shows the age and sex distribution of the young people who died. Table 2 compares the ONS mortality statistics for the age matched population with the results of our study population. The standardised mortality ratio overall was 2.3 (95\% CI, 1.9 to 2.9 ), with the greatest excess mortality in the age group 1-4 years. Although the general mortality rate from all causes in the 1-19 year group has fallen gradually over the years of our study (from 0.30 to $0.23 / 1000$ population between 1990 and 1996; p < 0.01; ANOVA), there has been no reduction in the mortality rate among children and young people with IDDM (0.65 to $0.70 / 1000$ population 
Table 2 Death rates and standardised mortality ratios for 5 year age bands compared with annual age specific rates in the general population of England and Wales from 1990 to 1996

\begin{tabular}{|c|c|c|c|c|c|}
\hline & \multicolumn{4}{|l|}{ Age groups (years) } & \multirow[b]{2}{*}{ Total } \\
\hline & $1-4$ & $5-9$ & $10-14$ & $15-19$ & \\
\hline \multicolumn{6}{|l|}{ Deaths from diabetes } \\
\hline Male & 10 & 7 & 8 & 26 & 51 \\
\hline Female & 7 & 6 & 14 & 13 & 40 \\
\hline All & 17 & 13 & 22 & 39 & 91 \\
\hline \multicolumn{6}{|c|}{ Estimated diabetic population } \\
\hline Male & 3200 & 15200 & 29400 & 38300 & 86100 \\
\hline Female & 2600 & 8700 & 22300 & 30900 & 64500 \\
\hline All & 5800 & 23900 & 51700 & 69200 & 150600 \\
\hline \multicolumn{6}{|c|}{ Death rate/1000 (diabetes) } \\
\hline Male & 3.12 & 0.46 & 0.27 & 0.68 & 0.59 \\
\hline Female & 2.69 & 0.69 & 0.63 & 0.42 & 0.62 \\
\hline All & 2.93 & 0.54 & 0.43 & 0.56 & 0.60 \\
\hline \multicolumn{6}{|l|}{ Deaths (all causes) } \\
\hline Male & 3514 & 2047 & 2217 & 6994 & 14772 \\
\hline Female & 2545 & 1422 & 1606 & 2997 & 8570 \\
\hline All & 6059 & 3469 & 3823 & 9991 & 23342 \\
\hline \multicolumn{6}{|l|}{ Population $(\times 1000)$} \\
\hline Male & 9796 & 11913 & 11313 & 11268 & 44290 \\
\hline Female & 9325 & 11292 & 10697 & 10620 & 41934 \\
\hline All & 19121 & 23205 & 22010 & 21888 & 86224 \\
\hline \multicolumn{6}{|c|}{ Death rate/1000 (all causes) } \\
\hline Male & 0.36 & 0.17 & 0.20 & 0.62 & 0.33 \\
\hline Female & 0.27 & 0.13 & 0.15 & 0.28 & 0.20 \\
\hline All & 0.32 & 0.15 & 0.17 & 0.46 & 70.26 \\
\hline \multicolumn{6}{|c|}{ Standardised mortality ratio } \\
\hline Male $\quad(95 \% \mathrm{CI})$ & $8.7(4.2$ to 16.0$)$ & $2.7(1.1$ to 5.6$)$ & $1.4(0.6$ to 2.8$)$ & $1.1(0.7$ to 1.6$)$ & $1.8(1.3$ to 2.4$)$ \\
\hline Female $\quad(95 \% \mathrm{CI})$ & $10.0(4.0$ to 20.6$)$ & $5.3(1.9$ to 11.6$)$ & $4.2(2.3$ to 7.1$)$ & $1.5(0.8$ to 2.6$)$ & $3.1(2.2$ to 4.2$)$ \\
\hline All $\quad(95 \% \mathrm{CI})$ & $9.2(5.4$ to 14.7$)$ & $3.6(1.9$ to 6.3$)$ & $2.5(1.6$ to 3.8$)$ & $1.2(0.9$ to 1.6$)$ & $2.3(1.9$ to 2.9$)$ \\
\hline
\end{tabular}

CI, confidence interval.

between 1990 and 1995, with a single low value of 0.20 in 1996).

HOSPITAL DEATHS

Forty five children and young people died in hospital during treatment for DKA (18 male, 27 female; median age, 9 years; range, 1-18). Of these, 28 (12 boys, 16 girls; median age, 7 years; range, 1-14) died from cerebral oedema. Table 1 details the distribution of deaths as a result of DKA and cerebral oedema over the years; there is no significant variation over time.

There were a further nine deaths in hospital from DKA where cerebral oedema remains a possible cause (three male, six female; median age, 13 years; range, 1-19). For three of these patients no further details were received, and the death certificates recorded hypoxic brain damage with DKA, cerebral ischaemia with DKA, and DKA alone. In the other six, the history was atypical, and cerebral oedema did not appear on the death certificate. Four of these young people were older than those with classic cerebral oedema (ages 17-19).

Eight young people died in hospital from DKA without any evidence of cerebral oedema. Causes of death in this group included aspiration pneumonia, multiple organ failure, gastric perforation, and traumatic hydrothorax.

DEATHS AT HOME

Twenty six young people (17 male, nine female; median age, 17 years; range, 7-19 years) were found dead at home. A further eight (seven male, one female; median age, 18; range, 8-19 years) were found moribund at home and died either on the way to $(n=5)$ or very shortly after arrival at $(n=3)$ hospital. These two groups (total of 34 young people) have been analysed together. Figure 3 compares the age and sex distribution of this group with the children who died from cerebral oedema.

In 24 of these 34 patients, DKA, hyperglycaemia, or diabetic coma were the certified causes of death. In five patients, the blood glucose concentration at necropsy was $>30 \mathrm{mmol} / 1$ and ketones were present; in another five, the blood glucose was $>50 \mathrm{mmol} / \mathrm{l}$ with no record of the presence of ketones. In the remaining 14 patients, insufficient information was received to verify DKA. Two were new presentations of IDDM. Eight of the 24 had evidence of brain swelling and/or congestion (one with uncal grooving), a further two had a "heavy" brain, seven had a normal brain, and the remaining seven had no report on the state of the brain at necropsy. Aspiration of vomit was noted in three cases.

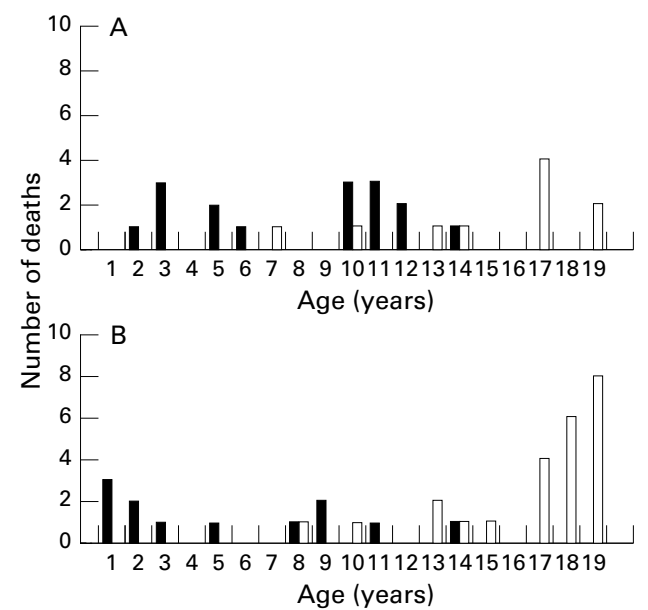

Figure 3 Number of deaths from cerebral oedema (closed bars) and in those found dead at home (open bars) (by age) in (A) female and (B) male patients with insulin dependent diabetes mellitus. 
In four of the 34 deaths, hypoglycaemia was the certified cause of death. In one there was no postmortem examination and no further clinical information. Of the remaining three, all had low vitreous humour glucose concentrations at necropsy $(0.7 \mathrm{mmol} / 1,1.4 \mathrm{mmol} / 1$, and undetectable). In two no history was available, and in the third, there was a history of possible hypoglycaemia the previous evening.

The remaining six deaths were the result of other or undefined causes. Three were certified as being caused by "diabetes mellitus"; in two no further details were given (and one did not have a postmortem examination), and in the third the urine glucose was high and vitreous glucose low $(1.1 \mathrm{mmol} / \mathrm{l})$. In one further case, hypoglycaemia had been noted during the previous evening, but the death certificate recorded focal myocarditis as the cause of death after a postmortem examination with no biochemical information. A 19 year male patient was certified as dying from staphylococcal septicaemia and a known epileptic was certified as dying from status epilepticus. Again no biochemistry was available.

Within the group of 26 found dead at their home, there was a subgroup of nine young people (seven female; two male; median age, 17; range, 10-19 years) who were found dead in the morning in an undisturbed bed having been apparently well the previous evening, fulfilling the criteria of the "dead in bed" scenario. ${ }^{8}$ Of this group, three had DKA according to our definition, one had a focal myocarditis with aspiration of gastric contents, and two were certified as dying from hypoglycaemia (with very low or absent vitreous glucose concentrations). The remaining three were certified as dying from hyperglycaemia $(n=2)$ and diabetic coma $(n=1)$, but no biochemical evidence was provided.

OTHERS

The cause of death did not readily fit into any of the previous categories in four cases. A 9 year old boy drowned in the bath while probably hypoglycaemic (blood glucose, $4 \mathrm{mmol} / 1$ during resuscitation). An 18 year old male patient died in circumstances suggesting a deliberate insulin overdose, another 18 year old male patient died from multiple injuries having jumped from a window accidentally while hypoglycaemic, and an 18 year old female patient died from coronary artery thrombosis, proved at necropsy.

\section{Discussion}

Our study has confirmed that IDDM in children and young people still carries a high mortality risk. Most deaths $(83 \%)$ were associated with DKA $(66 \%)$ or hyperglycaemia. The most common cause of death in children under the age of 12 years was cerebral oedema associated with treatment of DKA in hospital (25 of 36 deaths, with a further four possibly being the result of cerebral oedema). Three quarters of young people over the age of 15 years who died from IDDM were either found dead or moribund at home, and most of those also appear to have died in DKA. In contrast, the total number of deaths reported as being caused by hypoglycaemia was only seven.

Our calculated mortality rates are approximate because of the lack of a national diabetes register. However, the overall SMR of 2.3 is similar to that reported previously. Joner and Patrick $^{6}$ reported SMRs of 3.39 and 2.51 in the 10-14 and 15-19 year age groups, respectively, in Norway. Similar studies in Sweden report an SMR of 2.09 up to the age of 24 years $^{2}$ and, more recently, an SMR of 2.6-3.8. ${ }^{7}$ However, these studies were relatively small compared with our own. The highest mortality in our study was seen in the youngest children (1-4 years: SMR, 9.2). This contrasts with the results from Warner et al who reported an SMR of 2.96 in children aged $0-4$ years. ${ }^{4}$ This discrepancy might be explained by the fact that they included children aged $0-1$ year in their general population comparison group, which reflects the high perinatal mortality rate, and thus would obscure an excess number of deaths in the 1-4 year diabetic age group. If the normal infants under 1 year are excluded from their data analysis, the SMR is $\sim 13.7$. Therefore, the results of both of these studies show that very young children with IDDM are particularly at risk of dying from DKA, and our data indicate that the most likely cause of death is cerebral oedema.

The completeness of reporting of diabetes on death certificates has been questioned. ${ }^{12-15}$ However, a study from Denmark showed that ascertainment improved (95\%) if the patients were under 50 years and had IDDM. ${ }^{16}$ There is no information concerning the accuracy of reporting in children. Unfortunately, a recent register based study of mortality in young people in this country did not mention whether diabetes featured on all of the death certificates. ${ }^{4}$ One group of children who might not have diabetes recorded on the death certificate are those who died from completely unrelated causes. In our study there was a very low rate of accidental and suicidal deaths among this group compared with other reports, ${ }^{17}$ which might explain why the SMR in the age group 15-19 years was not as high as in previous studies. ${ }^{46}$ There might also have been a small number of children in whom the diagnosis of IDDM was never made or in whom diabetes was overlooked as a cause of death. The fact that the ONS sent us several death reports that had been miscoded is a concern, and it remains a possibility that our information is incomplete.

Cerebral oedema has been reported to be one of the common causes of death in young people with IDDM. ${ }^{17}$ Our study suggests that the proportion of DKA deaths in hospital as a result of cerebral oedema (now $62-82 \%$ ) has increased greatly since Scibilia and colleagues reported that cerebral oedema was documented in $31 \%$ of deaths from DKA. ${ }^{1}$ Thus, it appears that other causes of death in DKA are now less common. Although the number of deaths from cerebral oedema has not changed significantly over the past seven years, there were fewer deaths from this cause in 1995 and 
1996 , but it is too early to say whether this will be maintained. One of the aims of our study was to determine whether cerebral oedema was a feature of deaths outside hospital. Of the 24 deaths at home or occurring soon after arrival in hospital as a result of DKA, 10 had evidence of brain swelling. It has been reported that subclinical brain swelling might occur in most cases of DKA, even before treatment begins. ${ }^{17-19}$ Although cerebral swelling is a frequent postmortem finding in deaths from any cause, and might be a non-specific finding reflecting anoxia, in one of our cases there was uncal grooving, suggesting that raised intracranial pressure might have been the final cause of death. Thus, it is possible that cerebral oedema might cause death even in untreated cases of DKA.

Of great concern must be the large number of young adults, particularly boys/men, with poorly controlled IDDM who died at home. There has been much debate about a possible increase in numbers of young people found dead in bed, ${ }^{8}$ both in this country ${ }^{20}$ and in Scandinavia. ${ }^{721}$ The incidence of unexpected death at home in our study was $31 \%$, which is similar to the number recently reported from Sweden (nine of 33 deaths; 27\%). ${ }^{7}$ In our study, nine young people were found dead in bed, and in a further nine cases the location of the body was not specified. It has been suggested that unawareness of hypoglycaemia might be a contributing factor to these sudden unexpected deaths ${ }^{8}$ although this has been debated $^{1421}$; in the recent Swedish study, the authors concluded that hypoglycaemia was the most likely cause of death in their subjects because none had signs of DKA. ${ }^{7}$ However, in our study, of the nine who were found dead in bed, three had very high blood glucose concentrations with ketones, one further was certified as dying from hyperglycaemia, and hypoglycaemia was the certified cause of death in only two patients. Tattersall and Gill felt that a history of recurrent hypoglycaemia was helpful in deciding whether hypoglycaemia was a likely cause of death, ${ }^{8}$ but in only one of our nine dead in bed cases was a clinical history available of a possible hypoglycaemic episode the previous evening.

Determination of the exact cause of death in such cases might not be possible, partly owing to the difficulties in interpreting biochemical tests after death. The diagnosis of hypoglycaemia after death is particularly problematic. ${ }^{22}$ Samples from the right side of the heart might have spuriously high blood glucose concentrations because of continued glycogenolysis, whereas samples taken from the left side of the heart (including the peripheral venous circulation) might have spuriously low concentrations because of continued glycolysis after death. ${ }^{23}$ It has also been shown in dogs that vitreous humour glucose concentrations fall by $50 \%$ within three hours of death and are undetectable by six hours. ${ }^{24}$ Therefore, low or absent vitreous humour glucose concentrations cannot distinguish between well controlled IDDM and hypoglycaemia. ${ }^{8}$ However, grossly raised peripheral blood and vitreous glucose concen-

\section{Key messages}

- Children and young people with insulin dependent diabetes still have an increased mortality compared with the general population

- Diabetic ketoacidosis is the leading cause of death, particularly if it is complicated by cerebral oedema

- Hypoglycaemia is a rare cause of death even in those dying unexpectedly at home

trations probably indicate uncontrolled IDDM, particularly when associated with high concentrations of blood and urine ketone bodies. Three of those found dead in bed in our study had very high blood glucose concentrations (35-80 $\mathrm{mmol} / \mathrm{l})$ with ketones, concentrations that are unlikely to result from a Somogyi effect. Thus, although the final event causing death remains obscure, it is unlikely that it was related to hypoglycaemia.

Similarly, in about half of those found dead at home (but not necessarily dead in bed), raised peripheral blood glucose concentrations were documented together with high ketone concentrations in many. The fact that we did not receive biochemical information from all necropsies does not necessarily mean that it was not carried out, although there are variations in the extent to which a biochemical cause of death may be sought in a young person with known IDDM. The role that drugs and alcohol might have played in the deaths of these young people is also difficult to assess because drug and alcohol concentrations were only measured postmortem in seven of those found dead at home, but were only detected in small quantities in two cases.

In conclusion, mortality rates are still higher in children and adolescents with IDDM than in the general population. Large reductions could be achieved by a greater understanding of the aetiology of cerebral oedema, and by improving the care of young men with poorly controlled IDDM during the difficult transition from childhood to adulthood.

We are very grateful to the Office for National Statistics in England and Wales, the General Register Office for Scotland, and land and Wales, the General Register Office for Scotland, and
the Crown Office of Scotland. We would also like to thank C the Crown Office of Scotland. We would also like to thank C
Garbett for administrative help, Dr M Hawkins for statistical Garbett for administrative help, Dr M Hawkins for statistical
help, and particularly all the coroners, clinicians, and pathologists who have taken time and trouble to provide the valuable information. This work was supported by a research grant from the British Diabetic Association (Grant no: RD95/0001080).

1 Scibilia J, Finegold D, Dorman J, Becker D, Drash A. Why do children with diabetes die? Acta Endocrinol Suppl (Copenh) 1986;279:326-33.

2 Sartor G, Nystrom L, Dahlquist G. The Swedish childhood diabetes study: a seven-fold decrease in short-term mortality? Diabet Med 1991;8:18-21

3 Botha JL, Parker H, Raymond NT, Swift PGF. Diabetes diagnosed before the age of 2 years: mortality in a British cohort 8-17 years after onset. Int F Epidemiol 1992;21: 1132-7.

4 Warner DP, McKinney PA, Law GR, Bodansky HJ. Mortality and diabetes from a population based register in Yorkshire 1978-93. Arch Dis Child 1998;78:435-8.

5 Tunbridge WMG. Factors contributing to deaths of diabetTunbridge WMG. Factors contributing to deaths of

ics under fifty years of age. Lancet $1981 ; 2: 569-72$.
6 Joner G, Patrick S. The mortality of children with type I

Joner G, Patrick S. The mortality of children with type I
(insulin-dependent) diabetes mellitus in Norway, 1973(insulin-dependent) diabetes melli
1988. Diabetologia 1991;34:29-32. 
7 Sartor G, Dahlquist G. Short-term mortality in childhood onset insulin-dependent diabetes mellitus: a high frequency
of unexpected deaths in bed. Diabet Med 1995;12:607-11.

8 Tattersall RB, Gill GV. Unexplained deaths of type I diabetic patients. Diabet Med 1991;8:49-58.

9 Bingley PJ, Gale EAM. Incidence of insulin dependent diabetes in England: a study in the Oxford region, 1985-6. $B M \mathcal{F}$ 1989;298:558-60.

10 Gardner SG, Bingley PJ, Sawtell PA, Weeks S, Gale EAM and the Bart's-Oxford Study Group. Rising incidence of insulin dependent diabetes aged under 5 years in the Oxford region: time trend analysis. BMF 1997;315:713-17.

11 Breslow NE, Day NE. Rates and rate standardisation. Statistical methods in cancer research, Vol 2; the design and analysis of cohort studies. Lyon: IARC Scientific Publications, 1987:48-71.

12 Fuller JH. Causes of death in diabetes mellitus. Horm Metab Res 1985;15:49.

13 Waugh NR, Dallas JH, Jung RT, Newton RW. Mortality in a cohort of diabetic patients. Causes and relative risks. cohort of diabetic patients.
Diabetologia $1989 ; 32: 103-4$.

14 Stephenson J, Fuller J. Hypoglycaemia as cause of death in human insulin era. Lancet 1990;335:61.

15 McNally PG, Raymond NT, Burden ML, et al. Trends in mortality of childhood-onset insulin-dependent diabetes mellitus in Leicestershire: 1940-1991. Diabet Med 1995; 12:961-6.
16 Borch-Johnsen K, Kreiner S, Deckert T. Mortality of type I (insulin-dependent) diabetes mellitus in Denmark. Diabe(insulin-dependent) diab

17 Krane EJ, Rockoff MA, Wallman JK, Wolfsdorf JI. Subclinical brain swelling in children during treatment of diabetic ketoacidosis. N Engl f Med 1985;312:1147-51.

18 Hoffman WH, Steinhart CM, El Gammal T, Steele S, Cuadrado AR, Morse PK. Cranial CT in children an adolescents with diabetic ketoacidosis. Am $\mathcal{f}$ Neuroradiol 1988;9:733-9.

19 Durr JA, Hoffman WH, Sklar AH, El Gammal T, Steinhart CM Correlates of brain oedema in uncontrolled IDDM. Diabetes 1992;41:627-32.

20 Campbell I. Dead in bed syndrome: a new manifestation of nocturnal hypoglycaemia? [editorial]. Diabet Med 1991;8: 3-4.

21 Borch-Johnsen K, Helweg-Larsen K. Sudden death and human insulin: is there a link? Diabet Med 1993;10:255-9.

22 Marks V. Hypoglycaemia - real and unreal, lawful and unlawful: the 1994 Banting lecture. Diabet Med 1995;12: 850-64.

23 Gormsen $\mathrm{H}$, Lund A. The diagnostic value of post-mortem blood glucose determinations in cases of diabetes mellitus. Forensic Sci Int 1985;28:103-7.

24 Schoning P, Strafuss AC. Post-mortem biochemical changes in canine vitreous humour. F Forensic Sci 1980;25:53-5. 